\title{
Transforming Strategy Into Action on Integrated Project Delivery (IPD) Projects
}

\author{
Derek H T Walker ${ }^{1 *}$
}

\begin{abstract}
This paper reflects on four studies of integrated project delivery in which 80 expert IPD practitioners were interviewed. Taking an institutional theory perspective with a focus on the cultural-cognitive pillar, this paper discusses how people make sense of complex situations and how they interpret what is the right course of action to take. The paper explores how their cultural-cognitive skills assists them and identifies four key elements that helps explain the development of a unified-team best-for-project mindset.
\end{abstract}

\section{Keywords}

Integrated Project Delivery (IPD), alliancing, institutional theory, Cynefin Framework, Collaboration

\footnotetext{
1*RMIT University, Melbourne, Victoria, Australia, derek.walker@rmit.edu.au (Corresponding Author)
} 


\section{Introduction}

Integrated Project Delivery (IPD) is defined as:

“... a project delivery approach that integrates people, systems, business structures and practices into a process that collaboratively harnesses the talents and insights of all participants to optimise project results, increase value to the owner, reduce waste, and maximise efficiency through all phases of design, fabrication, and construction." (American Institute of Architects - American Institute of Architects - AIA California Council, 2007, cover page 2).

IPD enables an integrated united team project team approach to translate strategy into united action. It has significant and critical advantages over traditional approaches that rely on individual specialist project delivery team accountability being managed by a coordinating team (Aapaoja et al., 2013; Brady et al., 2005). Bygballe et al. (2015) undertook cross-case study analysis of various forms of IPD projects in the USA and Norway. They demonstrate a sophisticated interplay between formal and informal coordinated collective action using an integrated team of specialist teams united by an agreed common outcome project goal.

Other researchers have focussed on integration and collaboration through use of building information modelling (BIM) design. Fischer et al. (2017) provide numerous advantage examples of IPD teams collaborating through a common BIM platform while being physically co-located: enabling an exchange of ideas and perspectives to develop practical and workable design solutions. However, despite recent research of IPD team collaboration and how it facilitates more effective project delivery, there is still a paucity in understanding how teams reach a common purpose.

Projects may be considered as temporary institutions able to be investigated through an institutional theory lens (Henisz et al., 2012; Morris and Geraldi, 2011). How strategy is translated into action may be explained by the interaction of three institutional activities of building, maintaining and dismantling institutions through regulative, normative and cultural-cognitive institutional pillars (Scott, 2001; Scott, 2014). Hall and Scott (2019) use institutional theory to describe Sutter Health in the USA as an institutional entrepreneur that has enacted change in the way that problems are identified, conceptualised and solved through championing radical innovation in contractual forms that transform institutionalised roles, and relationships in construction projects. Biesenthal et al. (2018) trace a series of papers from early in this century, that take an institutional theory lens to study projects and the way that re-thinking how projects may be delivered to liberate interpretation of regulations, standards and what have been immutable laws and unleash a creative dialogue between parties, hitherto constrained by traditional beliefs of 'correct' institutional separation of contract parties engaged in project delivery.

Tukiainen and Granqvist (2016) discuss how project participants act and react when delivering transformational change project/programme projects. Others, (Matinheikki et al., 2019), have used institutional theory to study how Finnish teams from different professional backgrounds engaged in project delivery adapt their professional culture to form a 'project-specific culture' and Mahalingam et al. (2011) used institutional theory to discuss how the prevailing traditional safety culture on Indian rail projects has been challenged. Another Finnish example was based on the front-end stage of a healthcare provision project requiring agenda setting for collective action between different project participants in a project network organisation (Matinheikki et al., 2017). These studies highlight the cultural-cognitive pillar as a critical element in understanding the mechanisms in place that allowed project participants to adapt their normative perspective of the regulative institutional pillar to collaborate in taking collective action to achieve common goals. Some teams seem to collaborate well while others struggle. This may be explained by how they adjust their role perception and responsibilities to others. Institutional theory provides a useful lens to scrutinise how people interact.

Figure 1 illustrates the process of transforming IPD project strategy into action and identifies the role of the three institutional theory pillars and how they explain collaboration. The cultural-cognitive 


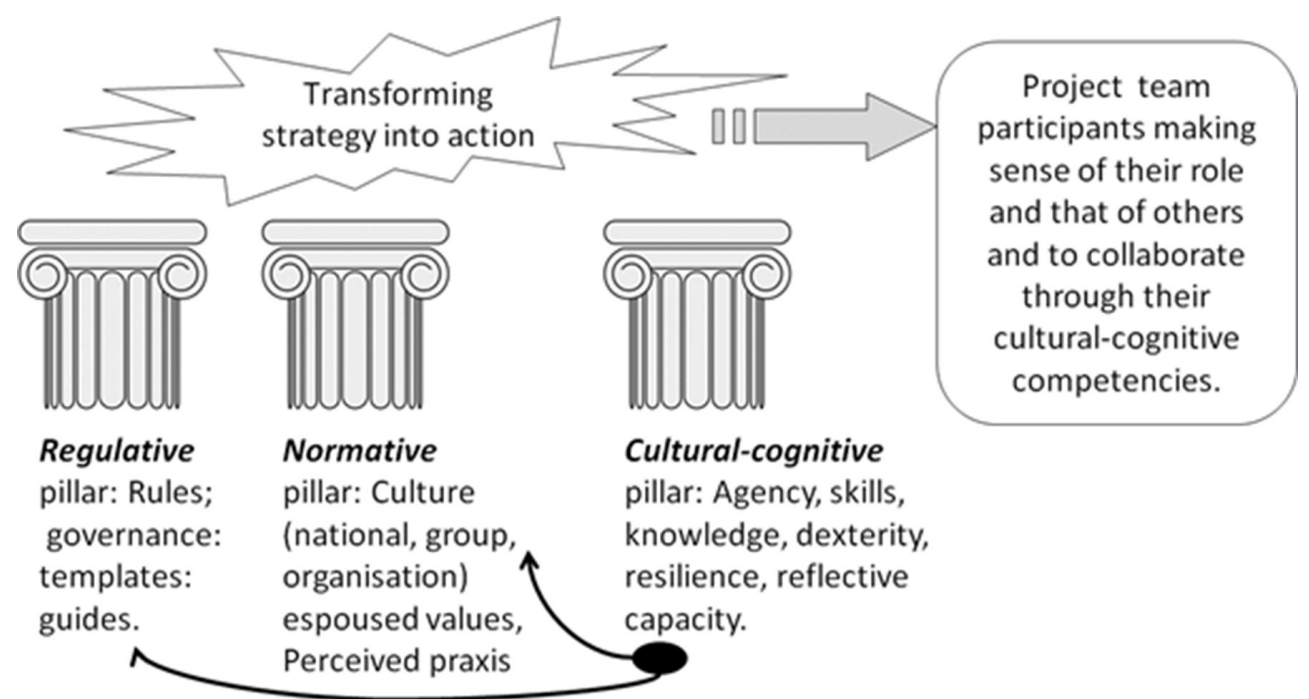

Figure 1 Transforming Strategy into Action seen from an Institutional Theory Perspective. (Source adapted from: Walker and Lloyd-Walker, 2020a, p. 23).

pillar is a critical factor shaping how project team participant sensemaking takes place. We still have a paucity of literature explain how participants engaged in IPD engage in dialogue to liberate their creative energies when faced with re-interpreting the rules, standards and templates to liberate themselves of constraints common to traditional project delivery forms. Several recent IPD research studies provide adequate and ample data that may help us explain how the cultural-cognitive capability of IPD project participants effective operates to harness their creative problem-solving capabilities. This presents opportunities for a point of departure and make a new contribution to our understanding of IPD practice through applying an institutional theory lens.

Therefore, the research question is:

Which mechanisms, behaviours and processes actively support integrated project delivery participants to make sense of project governance rules and protocols in a way that enables them to collaborate and forge common goals that results in unified collective action.

\section{Governance and the Regulatory Pillar of Institutional Theory}

The first pillar that supports institutional theory, according to Scott, is the regulatory pillar. This is characterised by explicit governance processes that he explains as 'rule-setting, monitoring and sanctioning' governance activities. Also, 'In this conception, regulatory processes involve the capacity to establish rules, inspect others' conformity to them, and, as necessary, manipulate sanctions - rewards or punishments - in an attempt to influence behaviour' (Scott, 2014, p. 56).

Müller (2017, pp. 12-13) conceptualises governance in terms of being about: 1) a system of controls; 2) processes; and 3) relationships. Andersen et al. (2020) describe governance from the following perspectives:

1. a set of controls - the viability and value proposition of the project is continuously monitored against set key results areas (KRAs) and key performance indicators (KPIs);

2. process - mechanisms of monitoring and control are established and followed;

3. motivation - incentives are used for gain/ pain sharing based on project outcomes;

4. relational-confidence, trust and desire to work together in the future is sought and facilitated; and

5. governmentality - the 'mentalities, rationalities, and ways of interaction chosen by those in governance roles to implement, maintain and change the 
governance structure' (Müller, 2017, p. 20).

Governance 'reality', experienced by IPD participants, can aid understanding how people rationalise their attitudes, behaviours and actions and how they perceive governance as a regulatory institutionalisation pillar. Does governance represent the 'black and white' rules of the game? Taking a narrow perspective such as 'governance is purely about control' may be highly limiting.

Fundamental principles of governance demand ensuring realisation of the project value proposition. Different parties to a transaction may perceive project outcomes quite differently depending on their value system and how they perceive reality of the governance system (governmentality).

A project's governmentality profile may be mapped, as shown by Müller et al. (2016), to illustrate three explanatory components. First, is the nature of governmentality. Second, is the nature of governance (the level of sovereignty or independence the team has) and governance mechanisms (relating to trust, control or a balance between these two points); and number of institutions. Third, is the nature of the context in terms of its level of projectification.

Figure 2 illustrates a notional mapping for IPD alliancing that illustrates a tendency to indicate a neo-liberal approach characterised by hybrid best-for-project and project and organisationalprofessional-personal values, medium-to-high sovereignty or team independence, balanced trustcontrol and a high number of institutions that may have a range of competing and complimentary values and world views and be highly projectfocussed. This mental model of the governance 'reality' experienced by IPD participants can

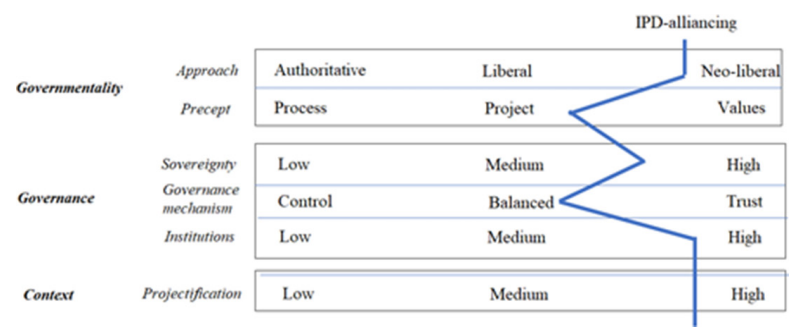

Figure 2 Mapping Governmentality of IPD. (Source adapted from: Müller et al., 2016, p. 964) help us understand how people rationalise their attitudes, behaviours and actions in relation to how they perceive governance in terms of a regulatory institutionalisation pillar. Does governance represent the 'black and white' rules of the game? We can see, therefore, that taking a narrow perspective such as 'governance is purely about control' can be highly limiting. If we think about the fundamental principles of governance, we can appreciate that it is about ensuring that the project concept value is realised.

Rowlinson and Walker (2020) discuss value within an IPD context in depth and observe that public sector projects often emphasise social and environmental value outcomes. Projects such as the Level Crossing Removal Programme (LXRP) had a KRA devoted to 'legacy': leaving the community neighbouring and along the affected rail lines and crossing with better amenities than that found prior to the crossing removals. Other KRA value outcomes included value co-creation through collaborative learning and developing trusting relationships.

Governance measures may be articulated by a client as being limited to monitoring and control mechanisms or regulation processes. However, in practice, these may be interpreted more widely by other project team participants: particularly in IPD projects where all parties to the project contract share different aspirations but need to agree on a common prime objective. The governance perspective and mechanisms may have a significant impact on how IPD participants view and respond to them and how they view the legitimacy of a project's regulatory institutional pillar.

Questions that presents themselves within an IPD context are: how can the project KRAs best represent not only the project owner's value proposition but also resonate with other IPD participating teams? How can the governance mechanisms be shaped for common action towards goals that best address the value propositions of all IPD parties, including the project owner?

Walker and Lloyd-Walker (2015, 2020a) identify a common governance structure as a key element that differentiates IPD forms of project delivery from other forms - arguing that 'Having a unified way that each project delivery team party legitimises its actions through rules, 
standards and norms, values and coordination mechanisms such as organisational routines, and the way that committees, liaison and hierarchy represents a unified or complimentary way of interacting' (2015, p. 144). A joint governance structure enables the whole IPD team entity to share a common commitment to a best-for-project outcome. Thus, the IPD team needs to determine the 'rules and regulations' that ensure that outcome. The project owner will outline the intended general project outcome in the project request for tender submission, with stipulated KRAs. The way that these are defined, translated and KPIs developed, is undertaken through the target outturn cost (TOC) co-creation of value process where the definition of what value means is defined (Walker and McCann, 2020b).

The above suggests that rules regulations and governance are far from a black-and-white definitive prescription of how to proceed on IPD projects. The regulative institutional pillar is in effect a guide and not a prescription. KRAs outline provisional and aspirational performance areas that need KPIs that can best indicate and not determine what performance has been achieved. The regulatory institutional pillar needs to be interpreted. Interpretation involves judgement based on a value system (culture) and often requires negotiation and co-determination of meaning. Further, as shown by Walker and LloydWalker, 2015, p. in the Collaboration Framework Element 7 Trust-Control Balance (2015, Table A13 pp. 188-190), there is a balance made in alliancing between autonomy and trusting the team. They note that the team and all team participants are also subject to and aware of governance requirement and probity processes that protect the integrity of all project so that parties to not adopt opportunistic behaviours or are negligent.

\section{Culture and the Normative Institutionalisation Pillar}

Scott maintains that the normative system defines 'goals or objectives (eg, winning the game, making a profit) but also designate appropriate ways to pursue them (eg, rules specifying how the game is to be played, conceptions of fair business practices)' (Scott, 2014, p. 64). The norms that project participants abide by, inform the mechanism by which they act. Culture provides the lens in which they perceive the world to guide their behaviour, belief system and rational for action that they take. Schein (1985) defines culture as the way that we do things here recognised at three levels. At a surface level it may be manifested by observable identifying artefacts such a uniform, or other collective symbols, that bind groups of people together. At a deeper level, identity is based on shared values and ways of seeing the world. At the fundamental level, culture represents foundational assumptions about the world as they see it.

Walker and Rowlinson (2020c) describe culture from an IPD perspective and argue that projects inhabit and world of cultures where people bring important influencing cultural elements including their national heritage, profession, organisation and their individual culture that evolves through sense made by their experience of the world. This has a profound impact on how they act and react. It also has a significant impact on the way they perceive rules, regulations and governance measures. Matinheikki et al. (2019) identify a general 'administrationgovernment' participant culture that led the project owner to see the purpose of the governance arrangements and KRAs as primarily serving the public good. The design team held an aesthetic culture where design excellence was critical to them and they defined quality, compliance and fitfor-purpose performance through that cultural lens. The contractors had a culture of pragmatism and saw financial and business sustainability as a key driving mechanism for performance. This project required the alliance participants to form a shared single team culture. However, Matinheikki et al. (2019) observed, all participants adapted their view by interpreting governance demands with a best-for-project mindset and their personal cultural preferences of what 'the right thing to do' meant in this project's context.

The process undertaken by participants undertaking dialogue to arrive at an ontological position that they are comfortable with is a highly complex psychological one. It requires respecting regulatory arrangements while pragmatically 
delivering the project despite being required to deliver on diverse and often seemingly conflicting KRAs.

Dialogue is vital, reflecting the ability to accept and understand the perspective of others engaged in dialogue. Dialogue is not about one person convincing another of their position. It is about parties exploring how they each see an issue and through discussion, exploration and mentalmodelling they arrive at a position that neither party may have initially considered had they not been able to explore that issue safely (Senge, 1990, p. 241). This requires team participants engage in true dialogue to have a perspective taking capacity and capability for within a psychologically safe environment. Perspective taking refers to the ability to empathise and understand the context, pressures, opportunities and motivation that govern how parties think, act and react (Parker et al., 2008). This quality requires people to be aware of themselves and their impact on others as well as understanding what makes others 'tick'. Perspective taking requires an open mind as well a sense of what has been recently become to be known as mindfulness. Good et al. (2016) observes that mindfulness 'involves attention to the internal (eg, thought, emotion) or external stimulus itself in a registering of the facts observed. Thus, perspective taking involves people not only thinking about themselves and what they see as 'correct' but also appreciating that others see thing differently as they reflective upon feelings, emotions, knowledge, insights and experiences. Often the result of such a process leads to creative and unexpected solutions to issues.

Emotionally and psychologically safe workplaces are characterised by low power and information asymmetry and supportive collegial relationships. They permit (and alliances even encourage) people to question assumptions and to think unconventionally to solve problems as they surface rather than hiding 'bad news' and engaging in blame shifting. Additionally, a mutual advantage in joint accountability and responsibility provides motivation and authority to experiment and learn from mistakes as well as from successes achieved. IPD alliance contracts contain specific ' $w e$ ' rather than ' $y o u$ ' language that clarifies that 'we the integrated team' are responsible for project delivery and not 'you' the designer for your part, 'you' the builder for your part (Department of Infrastructure and Transport, 2011).

Aculture of trusting a person's expertise enables and supports their ability to freely discuss ideas, challenge assumptions and collaborate with others to arrive at innovative problem solutions. Trust and the willingness to allow people sovereignty over their working conditions to be resilient and proactive, rather than be stymied by having to follow a set of rigid regulations, has been shown to be an important element in supporting collaboration.

A workplace culture represented by high trust and commitment towards employees, combined with organisational sanctioning of experimentation and a no-blame environment, offers opportunities to take immediate action as soon as problems are identified and learn from mistakes as soon as they become apparent: rather than hiding them. This allows organisational learning to take place. Snowden in his Cynefin Framework (Kurtz and Snowden, 2003; Snowden and Boone, 2007) demonstrates that in complex situations there are many unknown unknowns and unknowable unknowns in chaotic situations. Clearly, culture in its holistic sense, mediates how the regulative institutional pillar is understood but how is this done?

\section{Sensemaking Practice Through Use of the Cultural-Cognitive Pillar}

According to Weick et al. 'Sensemaking involves the ongoing retrospective development of plausible images that rationalise what people are doing. Viewed as a significant process of organising, sensemaking unfolds as a sequence in which people concerned with identity in the social context of other actors engage ongoing circumstances from which they extract cues and make plausible sense retrospectively, while enacting more or less order into those ongoing circumstances' (Weick et al., 2005, p. 409). Thus, people's sensemaking informs how they interpret their world to take appropriate action that fits their value system. Figure 1 illustrates the cultural-cognitive institutional pillar characterised by people's agency, skills, knowledge, dexterity, resilience and reflective capacity to consider the regulative pillar and make 
sense of what that requires of them given their norms and cultural predispositions. People make sense of what is expected of them and act (their agency) according to a perceive practical approach that is consistent with their perception of the drivers and inhibitors they confront.

Agency has been linked to power. Dietz and Burns (1992, pp. 191-194) identify four criteria that indicate an actor's agency: the actor must be able to make a difference; the actions must be intentional; there must be room for free play on the part of the actor; and the actor must be reflexive, in that they must be aware that they are exercising agency. Mullaly (2014) found that effective decision makers considered themselves as flexible, resilient or exercising initiative and followed rules and processes pragmatically with a focus on the fit and relevance of the rules and regulations to the perceived context. This suggests that multiple actors, each with their own sense of agency and what their cultural norms lead or guide them to do, may influence each other. Through dialogue, the resulting collective agency may be shaped as a hybrid of the approach that each participant in the dialogue may otherwise have followed (see Matinheikki et al., 2019).

Following Snowden and his Cynefin Framework concept, sensemaking and appropriate implementation of the cultural-cognitive institutional pillar is seen as highly appropriate in complex or chaotic situations. The Cynefin Framework identifies four domains/situations to describe the level of knowledge and appropriate responses to those domains. The simple/obvious ordered domain holds few surprises: patterns and processes are clear, usually stable and the context and expected response is well known. Mainly following the regulatory institutional pillar more literally with limited consideration of variations in project team norms may be appropriate. The second ordered domain is complicated and is characterised by cause-and-effect patterns being discernible usually with several viable solutions with required knowledge being available. Rules and templates may be followed but they usually require some level of adjustment and discretionary action often after a process of dialogue with experts. The third domain is complex or highly complex with many aspects of the context being unknown and parties involved being unaware of what they don't know. Patterns of cause-and-effect are absent and so there is little point in following rules and regulations. The appropriate response is to try to radically adapt rules with agency being exercised as a series of experimental responses being made with close and rapid monitoring and dialogue with others to help make sense of emerging patterns so that actions may be dampened or escalated. There is a high level of reliance on attention to the cognitivecultural institutional pillar and consideration of the impact of action on the many cultures and subcultures surrounding a project. The fourth domain is chaotic where much is unknowable. There is no sense of understanding patterns of cause-and-effect the response is to create rules and try to force the situation into the complex or complicated domain where some level of agency is possible. A fifth domain of disorder is noted where people do not know which domain they are confronting.

Snowden cautions us to beware of the prevalence of being in the disordered domain. $\mathrm{He}$ argues that often people blindly follow their preferred default response. This may be triggered by powerful cultural drivers that may blind us to the reality of the situation. For example, those with a highly rigid bureaucratic cultural disposition will see the situation as one in which the rules and regulations need to be more strongly emphasised and this often leads to a false sense of control and actions that exacerbates bad situations.

The Cynefin Framework helps us better understand the cultural-cognitive institutional pillar workings. In simple situations people generally follow the rules by reference to their cultural biases and influences, however, there is probably good reason to follow the rules as explicitly stated. Similarly, in complicated situations the rules generally make sense, but a better understanding of the context may lead to a need for some adaptation and modification, again based on cultural perceptions of what the rules mean. In complex situations the rulebook is either abandoned altogether or at least radically adapted because despite any cultural pressure to conform to the letter, the situation is blatantly not covered by the rules. It is difficult if not impossible to perceive 
Table 1 Expertise and wisdom development

\begin{tabular}{|l|l|l|l|l||l|}
\hline & Novice & $\begin{array}{l}\text { Advanced } \\
\text { beginner }\end{array}$ & $\begin{array}{l}\text { Competent } \\
\text { performer }\end{array}$ & Proficient performer & Expert virtuoso \\
\hline Experience & $\begin{array}{l}\text { Nervous about new } \\
\text { experiences }\end{array}$ & $\begin{array}{l}\text { Experience } \\
\text { may provide } \\
\text { uncomfortable } \\
\text { pork experience } \\
\text { paradoxes }\end{array}$ & $\begin{array}{l}\text { Confident about } \\
\text { ability to make } \\
\text { judgement calls }\end{array}$ & $\begin{array}{l}\text { Rapidly perceives } \\
\text { situational context }\end{array}$ \\
\hline Action base & $\begin{array}{l}\text { Relies on the } \\
\text { 'rules', rote- } \\
\text { learning and } \\
\text { training }\end{array}$ & $\begin{array}{l}\text { Recognises some } \\
\text { relevance to rules. } \\
\text { Some action } \\
\text { learning. }\end{array}$ & $\begin{array}{l}\text { Ability to work by } \\
\text { thinking on one's } \\
\text { feet. }\end{array}$ & $\begin{array}{l}\text { Reflection and } \\
\text { systems. Mixed } \\
\text { cognitive and } \\
\text { intuition influences }\end{array}$ & $\begin{array}{l}\text { Almost entirely } \\
\text { intuitive and } \\
\text { emergent based on } \\
\text { wisdom }\end{array}$ \\
\hline
\end{tabular}

cause-and-effect patterns and so an experimentand-rapidly-review approach is the only logical (and probably emotional) path to follow. When faced with a chaotic situation temporary rules need to be created with one logical option being to try to manoeuvre the situation back into the complicated or complex domain and act according to those contexts. Sometimes complete out-of-the-box innovative solutions are triggered by this situation.

The way that people react to challenges posed in interpreting the regulatory pillar can be explained by their level of proficiency and reflective experience of situations. Dreyfus and Dreyfus make the point that ability and confidence to effectively interpret rules and practice (Dreyfus et al., 1986; Dreyfus, 2004) is linked to andrological development. Cicmil (2003) also applied this theory in her $\mathrm{PhD}$ thesis relating to project manager expertise and wisdom development. Career development towards wisdom is seen as a five-step process as illustrates in Table 1.

Table 1 illustrates how experience and ability to make effective cultural-cognitive assessment of regulations and rules and so-called best practice develops. A novice encountering a new situation experiences stress, uncertainty and has great concerns about doing the 'right thing'. They are unsure of what that means leading them to rely heavily on their cultural norms to guide 'best practice' according to the rules. This leads them to over-emphasise the regulatory framework pillar of institutionalisation and often over-ride some cultural pressures such as dealing with ethical dilemmas. While regulations, training in 'best-practice' and cultural influences play a part, Advanced Beginners still tend to be cautious and heed the rules because they believe that rules trump any consideration of cultural imperatives influencing them interpreting these rules more fully to fit with the perceived context. Competent performers think on their feet and are more aware of contextual paradoxes that may challenge the application of regulations and rules as they perceive them. However, the context may overwhelm them. This is where the importance of dialogue with colleagues whose respected and trusted experience and judgement is evident. Proficient performers confidently grasp most contextual issues that impact choices about how to apply rules given the organisational, workplace, their professional and personal culture. Expert virtuosos immediately grasp both the situational context and cultural influences and rapidly respond and adapt to or re-invent (and often justify when required) the rules. Their ability to manage highly complex and chaotic situations is based on a highly nuanced cultural-cognitive quality of wisdom.

This explains personal attributes and characteristics relating to people and their culturalcognitive abilities but what of the organisational and environmental influences that impact individuals and their preferred response? Enabling people to most effectively apply their cultural-cognitive thinking to guide effective decision making and action relies heavily on the organisational environment encouraging initiative and being supportive. IPD and specifically alliancing project delivery forms display different characteristics to traditional business-as-usual competitive approaches. The workplace culture can be affected by its inherent degree of hierarchical power and 


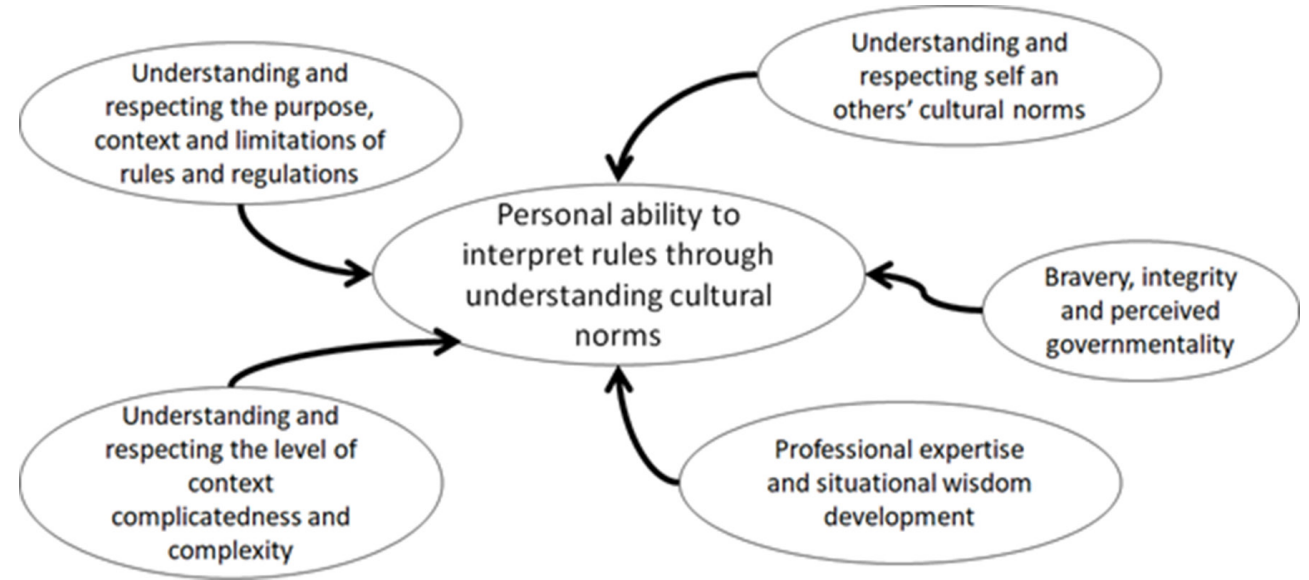

Figure 3 Cultural-cognitive capability.

information asymmetry, trust and control balance, system rigidity level as well as its position of its perceived legitimacy to control the lives and minds of employees and contractors.

Figure 3 illustrates the influences that impact a person's cultural-cognitive capability. It presents several important elements explaining a person's cultural-cognitive ability.

People need to navigate a path through rules and regulations, guidelines and prescriptive policy and still retain their sense of integrity. Understanding the purpose of the regulatory framework and its contextual limitations is important. Also, understanding and respecting one's values and the cultural norms of others is also vital in making sense of situations. Discussion on the Cynefin framework also suggests that a person needs to understand the situation level of complicatedness, complexity or chaos. A person's wisdom and expertise level also impact their likely response to a situation. Additionally, a person's culturalcognitive response is also conditioned by their bravery, integrity and their perception of a context's appropriate governmentality. Organisational explicitly expressed governance arrangements, and subtle influences embedded in its culture, need people to make choices about how they act and behave. Individual stages of professional expertise development also influence the way that people interpret rules, regulations and what doing the right thing actually requires of them.

Where is the evidence to support the way that IPD enables people to apply their cultural-cognitive expertise? Which mechanisms, behaviours and processes actively support project delivery participants to help them make sense of project governance rules and protocols in a way that enables them to collaborate and forge common goals that results in collective action? Evidence has been reported upon in the research studies outline in Table 2 and literature cited above. A selection of quotes cited in those studies is now presented with comments about how they address this paper's research question.

\section{Research Approach}

The purpose of this paper is to answer a howtype question and to do so from a sensemaking perspective. One of the co-authors of the four selected studies decided that it would be useful for the data to be re-examined to focus on how strategy is transformed into action through IPD teams' cultural cognitive ability. This presented opportunities of data availability and intense intimacy with that data and insights gained from conducting interviews with over 70 of the 94 experts interviewed in total over the four studies. Additionally, these four IPD studies involved a global catchment of insights with interviewees based in Australia, New Zealand, Finland, the USA, the UK, Netherlands and Sweden. Table 2 data sources draws upon the richness of expert IPD practitioner quotes describing how they made sense of regulatory demands and how that guided 
Table 2 Data sources accessed and used for this paper

\begin{tabular}{|l|l|l|l|}
\hline \multirow{2}{*}{ Source } & \multicolumn{3}{|l|}{ Interviews undertaken in studies } \\
\cline { 2 - 4 } & Practitioner expert & Academic experts & Study context \\
\hline $\begin{array}{l}\text { Study 1 - (Walker and Lloyd-Walker, } \\
\text { 2015) }\end{array}$ & 36 & & $\begin{array}{l}\text { USA, UK, Europe and Australia, } \\
\text { study based on a mixture of IPD } \\
\text { forms }\end{array}$ \\
\hline & & 14 & $\begin{array}{l}\text { Level Crossing Removal } \\
\text { Programme Alliance, Victoria, } \\
\text { Australia }\end{array}$ \\
\hline Study 2 - (Walker et al., 2018) & 5 & & $\begin{array}{l}\text { Additional study to the 2015 } \\
\text { study 1 from Australia }\end{array}$ \\
\hline Study 3 - (Walker et al., 2016) & 20 & & Alliance study from Finland \\
\hline Study 4 - (Matinheikki et al., 2019) & 19 & & \\
\hline
\end{tabular}

their actions. Quotes from 80 expert practitioners together with insights from 14 academic subject matter experts provided a wealth of data with which to explain how expert IPD practitioners made sense of the regulatory framework. This paper is reflective in nature, the author went back to the source data and the four study's published findings to focus on how interviewees explained their approach to their cultural-cognitive sensemaking processes. It distills and highlights the influencing mechanisms, behaviours and processes that they accessed to make sense of rules, briefing instructions, KRAs, and alliance behavioural agreement requirements. In essence, this is a sensemaking paper about people who engage in sensemaking. Three strong themes were identified-personal, workplace, contractual and - that explain how personal and cross-team sensemaking and integrated collaboration was conducted by interviewees. These themes may be seen to develop cultural-cognitive expertise.

IPD mechanisms, behaviours and process are real and observable. Therefore, institutional theory may be considered as a concept that is socially constructed and can be viewed from a critical realist perspective. Somerville (2012, p. 291) contends that critical realism '... can be characterised as a combination of a realist ontology (or theory of being, of how the world is) with a fallibilist epistemology (or theory of knowledge, of how the world is known). Realism is the belief that reality exists independently of the human mind, with the latter being typically understood as perception (the observer), cognition (the knower), or thought (the thinker). Fallibilism is the belief that our knowledge of reality always has a chance of being proved wrong, that is, our knowledge has no sure foundations.' Somerville argues that '.. if we conceive the world as consisting of dispositions, series of events, and systems of relations, then we are able to make more and better sense of it.' This paper's objective is to understand how people in IPD projects, and complicated or complex projects in general, make sense of regulations, rules and governance based on their cultural pre-dispositions and ability to make sense of these regulations to deliver projects. Critical realism in this context acknowledges that the approach may be fallible but should be credible. Theory is thus used to reveal hidden powers - processes or mechanisms - that produce the effects or events selected from relevant research studies.

\section{Evidence From IPD Studies in Which IPD Practitioners Were Interviewed}

Discussion on mechanisms, behaviours and processes that actively support project delivery participants to help them make sense of project governance rules and protocols is focussed on six elements as illustrated in Figure 4. All Table 2 studies confirm that the cultural-cognitive pillar of IPD collaboration lies at the heart IPD behaviour and concerted action. How this is achieved is not made explicit in those studies, however, further analysis is undertaken for this paper explains how this level of sensemaking may occur using quotes from interviewees that illustrate cultural-cognitive mechanisms at work. 


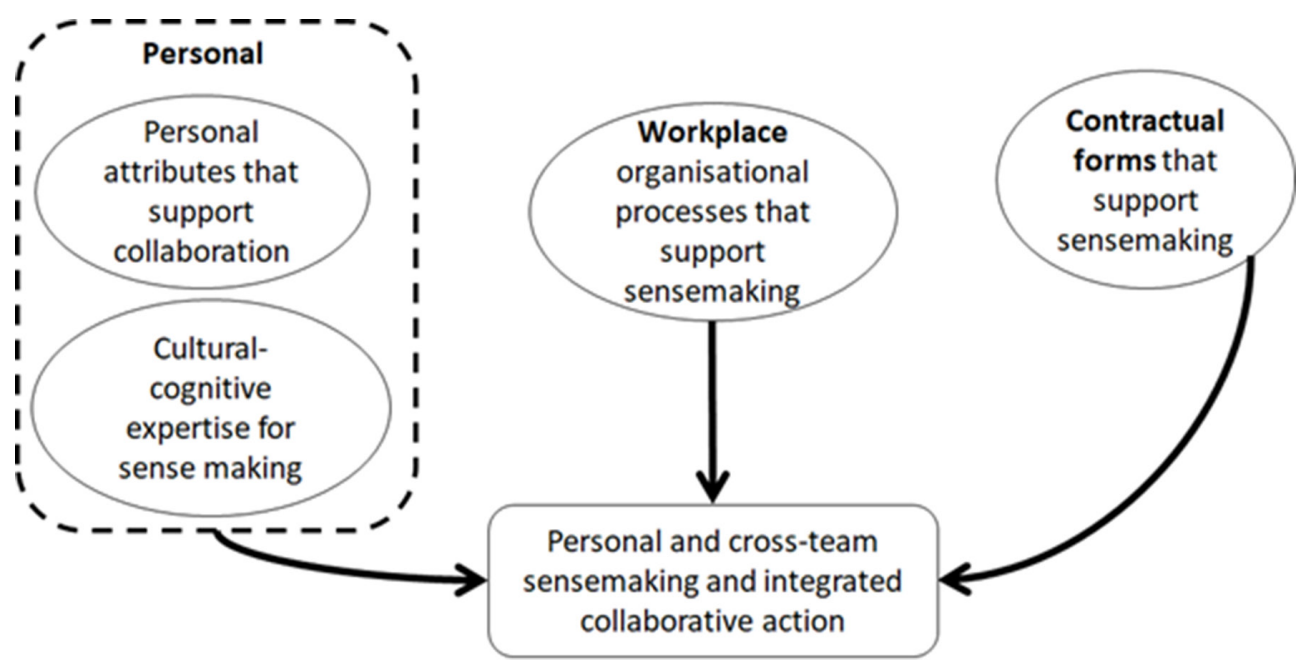

Figure 4 Conceptual model for cultural-cognitive expertise for an IPD context.

Three main element components are identified: personal; organisational; and contractual that impact people's ability within IPD projects to empower them, encourage them and support their initiative and resilience and help them shape through sensemaking, best-for-project collective action through their cultural-cognitive sense making expertise. These three components emerge from the data suggesting that, when effectively deployed, they positively impact teamwork by forming a cohesive, integrated and collaborative unified team. Participating teams pursue a dialogue process resulting in more inclusive, deeper and robust sensemaking. This allows coordinated and focussed action informed by the unified team's collective cultural-cognitive capability. These components and their impact on integrated focussed teamwork are explained further, citing interview transcript quotes.

\section{Personal Attributes}

Intent/motivation (attitude), ability and opportunity are important attributes in making sense of rules, regulations and the regulative pillar of project delivery. People may be willing and wish to make sense of the rules, and they have ability to do so, but they also need sufficient time, space and agency to reflect and apply their cultural-cognitive intellectual and emotional resources.

An attitude based on motivation and intent to question one's assumptions and reasoning provides a strong foundation for effective dialogue and cognitive-cultural reasoning. Table 2 studies, eg, Participant 23 from the first study said "I think an attitude more than anything, someone that was prepared to sit down and listen to both sides of this team and try and understand what the issues were" (Walker and Lloyd-Walker, 2015, p. 182). This suggests an open mindedness and willing of IPD practitioners to engaged in genuine dialogue when discussing with colleagues how rules and regulations should be interpreted as well as their reflective capacity to aid sense-making.

The Level Crossing Removal Programme of alliances (LXRP) study participant LXRP-1 stated “... there's also just the genuine getting behaviours right and trying to get the team to think as an alliance and try and put your respective ... hats to take them off. That cultural element is key. If you get that right you will have success, because the finger-pointing and the blame goes away and you get into problem solving, and usually that yields good outcomes, whereas, if you don't get the culture right, you're stuffed, you won't get there" (Walker et al., 2018, p. 28). In that study interview data clearly indicated that successful IPD practice involved personal attitudinal attributes of engaging in dialogue and collaboration formed a central feature of collective sensemaking.

“... there's also just the genuine getting behaviours right and trying to get the team 
to think as an alliance and try and put your respective ... hats to take them off. That cultural element is key. If you get that right you will have success, because the fingerpointing and the blame goes away and you get into problem solving, and usually that yields good outcomes, whereas, if you don't get the culture right, you're stuffed, you won't get there" (Walker et al., 2018, p. 28).

In that study interview data clearly indicated that successful IPD practice involved personal attitudinal attributes of engaging in dialogue and collaboration formed a central feature of collective sensemaking.

The third study compared the single versus dual target outturn cost (TOC) process to identify implications for collaboration. Several quotes reinforce the desire for collaboration highlighting the motivation of IPD practitioners to better understand and make sense of their colleague's approach to interpreting project governance measures. P37 illustrates the mind-set of IPD participants (Walker et al., 2016, p. 26) stating

"I've worked with the managing contractor role and in Adelaide and now on the framework agreement, and you will see the behaviours. You can certainly tell people who, from [Contractor X] or other organisations that come onto the team and have worked in an alliance, because you can just see their ability to, want to listen, understand, or try to understand what your motivation is and what your drivers are, versus just being very closed shop and just saying, well this is a driver and that's what we're doing".

In the fourth study, the client/project owner NTA, was experimenting with alliancing for the first time. The NTA's director is quotes as explaining the rationale.

"We [the NTA] had the courage and capability to interpret the public procurement legislation in a clever way. Everybody out there in other countries said that this was against the EU directives. But we have used our internal as well as external lawyers and they have said that there is no conflict. We just need to add a certain monetary component as one bidding criterion. Apparently, elsewhere, there has not been the courage or will to do this" (Matinheikki et al., 2019, p. 309).

This demonstrates how a cultural-cognitive sensemaking IPD example of the prevailing business-as-usual cultural (in this case EU bureaucracy) mindset being challenged. The client used both internal and external technical (legal) advisors to re-interpret the prevailing assumptions on what the EU directives may mean. This was a breakthrough for alliancing in Europe. More detailed history of this case of making an argument to the EU has been documented by Lahdenperä (2019, p. 132) (see his Figure 1). The Australian consultant is quoted as explaining how this all eventuated (Matinheikki et al., 2019, p. 310).

\section{Organisational Attributes}

Much of the trust and distrust literature is focused on perceived personal characteristics of the person to be trusted. Three core factors impact a person's perceived trust of another based on their perceived ability to perform as well as their integrity and their benevolence towards the person doing the trusting as indicated by the Mayer et al. (1995) seminal model. Other factors relating to the person doing the trusting include ambiguity and uncertainty of 'facts' that support the trust relationship such as what each party assumes to be true.

The impact of the organisational culture of both parties involved in trust is important, e.g. the level of suspicion or openness to trust others (Mayer et al., 1995) because this impacts the propensity to trust or be trusted. Culture, in terms of the institutional theory cultural-cognitive pillar may relate to biases or pre-conceptions of the individuals involved from a national cultural perspective. For example, certain national cultures may default to more rigid approaches to power and information sharing than others (Hofstede, 2001; House et al., 2004; Trompenaars, 1993). Occupational or professional cultures shape their member's world view of what is of value and what may or may not be trustworthy (Schein, 1996). The project owner organisation, designer and contractor partners may 
not initially share the same emphasis on what is of critical value (Matinheikki et al., 2019) and suspicion or acceptance/understanding of diverse views and values may arise because of culture and professional values. If one organisation forms the view that problems are on the horizon and an interacting organisation does not, then there is an inherent conflict and likelihood that one party may think that ' $\mathrm{OK}$ this organisation would normally be trusted to ... but, given X circumstances we don't think they will be able to ...'

Organisational culture may be partially based on its leader's national cultural traits typified by specific traits such as high levels of power/ knowledge asymmetry suggested by literature establishing links between national culture and attitudes to power/information asymmetry and trust in collaborations (Smits and van Marrewijk, 2012; van Marrewijk and Smits, 2016). Collective trust ranges from being a minor to a major factor depending on groupthink within that culture (Ahlstrom and Wang, 2009; Hällgren, 2010). Taking this organisational culture perspective, people moving from one organisation/role to another may increase their openness to understand the perspective of others from different organisations/ roles. It becomes clear that because organisations comprise many individuals who may choose to act independently while being part of an organisation, the interplay between the position of people and the organisation may result in 'chinks in the corporate armour'. Organisational cultural solidarity cannot be assumed.

A workplace cultural continuum ranges from being aggressively defensive, to no-blame (Lloydwalker et al., 2014; Provera et al., 2010). The impact of the organisation's value system is critical to how people will trust their employees. Trusting another person involves considering the person's inherent ability, integrity and benevolence and how that may be affected by their organisational culture pressures and influences. Promotion of an organisational no-blame stance, in alliancing for example, may result in a greater pressure to understand an adverse event from a system and individual/group responsibility perspective in order to learn from that event to take actions that are more holistically considered (Auditor-General of the Australian National Audit Office, 2000; Lloyd-walker et al., 2014, p. 41). An organisation considered to have an aggressively competitive or defensive culture is less likely to be open and inclusive. The organisational culture of an alliance IPD contract is more likely to be supportive of collaboration and a joint unified sense of responsibility and accountability because this is a prime criterion of selection of an alliance syndicate. The National Museum of Australia project had an alliance selection process in which one criterion was stated as demonstrated understanding and affinity for operating as a member of an alliance. Each participating company was required to provide examples of their working in a nonadversarial and collaborative manner as well as to demonstrate their views on participating on risk/ reward schemes. The willingness to wholeheartedly support and embrace the alliance philosophy was required. There was a focus on ideas, team working, sound past relationships and general knowledge about the alliancing concept' (Walker et al., 2002, p. 88). This illustrates the demands placed on the project alliance organisation and suggests that it was designed to encourage teams and individuals to trust each other. Organisations also support an alliance and other similar IPD forms by actively supporting individual and team training, development, mentoring and nurturing of the required 'soft skills' required of collaborative and integrated team (Lloyd-Walker et al., 2020, p. 256-257) to prepare team members to work collaboratively within a workplace characterised by trust and respect as well as low levels of power and information asymmetry.

IPD alliances are typically based on a collegial collaborative behaviours and closely integrated governance arrangement in which the value of a best-for-project mindset prevails (Department of Infrastructure and Transport, 2011). In terms of governance, two levels of project alliance participant steering committees are formed (Andersen et al., 2020). The Alliance Management Team (AMT) takes responsibility for the operational aspects of the project and are focussed on achieving the identified KRAs and steering the project to that end. It is composed of senior on-site representatives from the alliance partners including the Alliance 
Manager. The Alliance Leadership Team (ALT) takes responsibility for ensuring that the project's strategic goals are met. They comprise directorlevel representatives of the alliance team individual companies and are tasked with adjudicating on any project-operational issues that require settlement or confirmation at a senior management board level. Additionally, they support the alliance through being senior alliance participant members (Ross, 2003). They are often an influential conduit to the project-external political and economic world and can settle issues relating to resources requiring commitment from their home organisations. They also bring their project-external circles' influence to the alliance. These knowledge and network connections may prove vital when circumstances change, and plans need to be dynamic rather than static or rigidly applied.

Several quotes from the analysed studies support the role of organisations in preparing individuals to be able to make sense using their cultural-cognitive institutional pillar.

Participant 20 interviewee in the Walker and Lloyd-Walker study said

"Because the management team was quite balanced in terms of perspective, then it meant that we were able to have a robust discussion at the management team level. Then if we couldn't come to an agreement with the management team, then it would go to the leadership team, I would present it to the leadership team for approval, but honestly we didn't have to have the leadership team get involved in more than 10 of these things, and there have been hundreds over the course of the project, so much things have been able to be managed by the management team"' $(2015, p .201)$.

This illustrates how the governance AMT and ALT approach assisted in interpreting and making sense of the rules and project context and circumstances.

The LXRP study illustrates how an alliance organisation created a community of practice $(\mathrm{CoP})$ to assist in sensemaking across alliances within a programme of project. A CoP is an organised group of people who meet to share knowledge, insights and experiences (Lave and Wenger, 1991; Orr,
1990). Duryan and Smyth (2019). A CoP participant reported how a project-based organisation, with a programme of projects, successfully used a CoP to become more efficient, effective and resilient. In the LXRP case, the LXRP authority (LXRA) formed what they termed a Joint Communications Committee (JCC) that was tasked with meeting regularly to exchange ideas, insights and discuss common concerns. Interviewee LXRP-2 stated:

"So there's the joint coordination committee, which LXRA operate, which started (I think) on the regional rail alliance, and it's been used on the major agencies packages. I sit on alliance managers' sub-committee. The $J C C$ - the joint coordination thing - is all very senior people from all other programmes and projects, and then underneath there there's subject matter expert groups, there's an alliance manager group, there's a sustainability group, a design group, a construction group, and all of these equivalent positions from the different projects meet. But up until now - until this last programme has been awarded - we've all been in competition with each other to win projects, so now is the opportunity; now that all the projects are awarded we're not competing anymore - at least not to win projects, but competing to be better than each other, which is healthy - we can now turn up and we can share ideas and we can talk to each other and we can say "well how is your project..?"

The third study also presents insights into how organisations can support individual and group cultural-cognitive appreciation. Participant S-12 explained how the alliance organisation supported innovative thinking and fresh interpretation of rules and regulations within the alliance context.

"There's clear evidence of ground-breaking innovation in the fact that in many of the government agencies delivering projects, they have a technical wing. So, for instance [Agency A] in [State B] has a technical engineering standards group that was historically used for doing things in a very

Engineering Project Organization Journal

(C) 2020 Engineering Project Organization Society www.epossociety.org 
conventional standard sort of way. And the first sets of alliances they just continually push back against any innovations that were being brought to them, until one alliance we decided, well why don't we take these people on the journey right from the start and make them an internal stakeholder rather than an external checking body. And, all of a sudden, once they were involved in bringing innovations forward and developing them up and creating new standards for the organisation, they were a different animal and they were changing their own internal processes and standards. I mean that sort of change for the industry was a stunning thing which wasn't successful originally, but was an indication that these projects were pushing the boundaries. So you know the evidence is in how the government agencies themselves reacted in their technical wings. Some of the, quite frankly for the technical people, these alliance processes were a remarkable breath of fresh air for them (2016, p. 21)".

Matinheikki et al. (2019) study illustrates how the project organisation facilitates an integrated and collaborative approach to making sense of plans and priorities. The public relations (PR) manager who was interviewed described how diverse professional groups were blended in a single team to make sense of each other's priorities and motivations as well as developing a best-forproject plan. He said

"Orientation is one thing in which we introduce the fundamental principles of the alliance model. Then, we have these development days every now and then; for example, the next one is tomorrow. We organise these scheduling workshops in which we carefully analyse all the tasks to be undertaken during the next six months. There we have all the disciplines presentdesigners, contractors, and so on. And at the very beginning, we had this alliance training or coaching where we had an external consultant, $\mathrm{Mr}$ N.N. He also facilitates these scheduling days as well as some other workshops and joins the development days " (2019, p. 311).

These quotes explain how organisational attributes and action can shape how successful individuals may be in the cultural-cognitive abilities. Figure 3 indicates characteristics thatrelate to both individual (such as being trusting, motivated and respectful of others' expertise) and organisational characteristics (such as having collaboration-supporting processes and routines, allowing individuals to exercise initiative and agency within a no-blame workplace culture) that when positive, drive collaboration and when negative, build barriers to collaboration that in turn enables and facilitates cultural-cognitive sensemaking. One key inhibitor in facilitating free and open exchange to perform dialogue, to in turn make sense of 'the rules', is knowledge stickiness. Szulanski (1996) explains sticky knowledge as a tendency for new ways of thinking and acting being inhibited by difficulties people have in communicating and collaborating to learn from experience.

Personal and organisational characteristics are of limited value unless the organisation and all team members are facilitated to collaborate and share world views through dialogue. This may be achieved through the framing of a contract form that purposefully accentuates the collaboration drivers and dampens or extinguishes collaboration inhibitors. So how might a contractual form make a vital difference in improving individual and team cultural-cognitive sensemaking?

\section{Contractual Attributes}

The contract encompasses the regulatory pillar by framing the expected output of a project and what is acceptable in terms of behaviours and means to resolve disputes. This is where the IPD alliance approach markedly differs from that of traditional approaches to project delivery, particularly in the construction industry (Department of Treasury and Finance Victoria, 2009). Traditional construction delivery projects such as the design-bid-build or design and construct (D\&C) contains performance language that states that you (the designer or contractor) will be responsible and accountable for X. Alliancing and similar IPD forms adopt a 
collective form of language that states that we (the alliance that also includes the owner's participant and often the facility operator) will be responsible and accountable for $\mathrm{X}$.

This simple change of language, from you to we, has a profound impact on the way project parties will act. The main impact is that this makes explicit a joint responsibility and accountability for delivering the project KRAs. Alliance participants are jointly accountable. In traditional approaches the designer may see their role as ensuring that the design is acceptable, and the contractor may see delivery of the end product to contractually stated KRA standard as the limits of their responsibility.

IPD-alliance performance is framed by the KRA and so all participants need to collaborate to ensure that the end result is acceptable where all participants realise that they share mutual dependency and accountability and sink-or-swim together (Walker and Lloyd-Walker, 2015, p. 219-223). A further contractual agreement feature is that they have stipulated and specific participant behavioural requirements to support an organisational culture of low power and information asymmetry, high levels of mutual respect for expertise, requirements to challenge assumptions and be pro-active in innovation to improve performance and a culture that encourages learning from experimentation and unconventional thinking to resolve challenges (Department of Treasury and Finance Victoria, 2010). This contractual requirement is managed through selection and governance mechanisms. First, the selection process ensures that alliance syndicates putting themselves forward to work with the project participant is rigorous with key selection criteria, for example providing evidence based on the proponents' past record of being able to collaborate across disciplines as a unified team as well as collaborating with subcontractors and the on-site workforce (Walker et al., 2002, p. 92). Second, an alliance contract agreement contains KRAs that may include behavioural measures such as performance in incremental improvement through innovation or through sharing innovations across several alliance teams as occurs for the LXRP alliances (Walker et al., 2018).

An alliance agreement also contains clauses to incentivise the alliance team (Department of Treasury and Finance Victoria, 2010). The main incentive is a gain/pain share arrangement. The alliance team develop a target outturn cost (TOC) which is far broader than just a cost budget to undertake the work. It is a carefully crafted strategic plan that includes not only the material and service delivery cost including profit margins, but also the time target, scope of work, agreed quality standards and other KRAs. The profit margin is extracted from the TOC and is held at risk with agreement of all alliance participants on the risk distribution between them (see for example Walker and McCann, 2020b). The incentive for the alliance is to beat the TOC, which is fixed at authorisation and contractual acceptance. Any performance that is better than the TOC results in sharing the underspend gain based on the agreed distribution formula. Performance that fails to achieve the TOC results in any overspend pain being shared using the same formula and it is deducted from the profit margin bid within the TOC. The contract message is clear. Participants are jointly responsible for the project performance result and if any member of the alliance is beginning to show signs of underperforming, then it is in the interests of the other alliance participants to ensure a successful result. The contract 'fixes' the TOC with no opportunity for alliance participants to blameshift or to prepare claims for extra money or time. When challenges arise, the alliance team need to collectively respond and obviate looming problems. Thus, the contract becomes a collaboration and cross-discipline enabler of sensemaking of how governance rules may be interpreted in a context where sensemaking is more likely to support collaboration and unified action.

In the first study, participant interviewee P32 makes insightful points that illustrates sensemaking in an alliance programme, rather than project, sense where the rationale of how to behave may be influenced from a long-term perspective. P32 is quoted as saying

"... we had a set of KPIs and there's some performance gain share/pain share in this. The KPIs we've had from the outset were probably a bit too clunky, a bit too detailed, a bit too labour intensive, so we're currently looking at reviewing those to simplify those and better target the KPIs. Interestingly, we

Engineering Project Organization Journal

(C) 2020 Engineering Project Organization Society www.epossociety.org 
set the KPIs in terms of what behaviours we wanted to drive, we've found those behaviours were there at the outset anyway and indeed they haven't really achieved anything significant in their own right. And from the contractor's point of view, the first couple of years they've had a performance gain share and they've actually decided as a show of good faith to reinvest that in the road. So they've actually spent their profit on doing more road works because they see that as reducing the maintenance costs in the long term, best for their network. Which is a really good indication of their commitment. But it puts into focus what are these KPIs" (2015, p. 213).

This quote demonstrates high levels of culturalcognitive reasoning. The programme rather than project alliance culture led to sensemaking about a best-for-network rather than best-for-project outcome.

The LXRP study has interesting insights about how an alliance contract with its strict performance target triggered innovations that have now been rolled into best practice approaches for several other alliances now. Reflecting, as the alliance manager, on the relationship between his team and the ALT and Alliance director after they had to totally revise their strategy to meet the TOC end date after being delayed in their project start because of a longer than expected project alliance award approval process, LXPR-2 said:

“...250000 cubic metres of soil to dig out in 10 days, 35000 cubic metres of concrete to pour in six days. ... I'd go present to my CEO and I'd do the quarterly report and say 'this is what we're doing' and he'd look at me and he'd say 'really?' He never said 'you're bonkers, you're crazy, you can't do it' but it was always that 'really?' And it was just that confidence just to be able to sit there and say 'yeah, it's no problem, we've done this, this and this, we've got all the planning in place, it's sweet as, no problem" (Walker et al., 2018, p. 29).
The third study quote chosen for this paper for participant S-18 recalls how he and two other alliance participant experts P-25 and P-40 interviewed in Study 1 (Walker and Lloyd-Walker, 2015) influenced a decision to create an alliance for a complex mechanical and electrical tunnel fit-out component of a public private partnership (PPP) airport to city highway link project. They had worked together on a tradition D\&C basis on a similar previous project (referred to as $\mathrm{ABC}$ ) that had become a nightmare for all parties involved. The D\&C contract form encouraged individual team performance ahead of best-for-project performance. Each contractual party in the design and delivery teams did their job with their best interests at heart to maintain schedule. However, the systems integration between the civil, mechanical and electrical works provided severe challenges resulting in numerous contractual claims by a sub-contractor (referred to as E) against the main contractor due to interference and other coordination issues that delayed their access at critical times. The story unfolds that once the interviewed participant S-18 had a meeting with P-40 it became clear that the main issue was the form of contract and what it rewarded and upheld. The quote in the third study provides a longer explanation than is appropriate here so it is partially quoted. More detail is provided by Walker and Jacobsson (2014). S-18 highlights how the alliance IPD delivery form provided greater scope to more effective make sense of the contract given a workplace culture of collaboration and best-forproject mindset by stating:

“... I guess what you'd call an end of project squeeze where they went into the mechanical and electrical full of good intentions, the project slipped behind schedule, the squeeze came on mechanical and electrical and under the pressure of that squeeze, the relationship broke down and they had major claims and difficulties and fairly bitter claims came out of that, and what was most recent in the mind is with the claims that came out of [project $A B C]$. So the guys that I met were determined to create some kind of environment where that wouldn't happen again and I led them 
to, I guess the conclusion, that if they really wanted to create the conditions where they had absolutely no choice but to collaborate, why not make it a pure alliance?" (Walker et al., 2016, p. 30).

The fourth case study provides an example of how the framing of the Finnish alliance contract contributed to management sensemaking effort to be positively directed towards project delivery performance rather than being tied down by having to make sense of the contract to make or defend claims between parties. Alliancing contracts, unlike the North American IPD forms, have a no-litigation clause in them with the only exception accepted being for demonstrable incompetence or criminal behaviour (Ross, 2003, p. 2). Case study four cites a manager of a private sector contractor in that projects stating:

"Well, if I exaggerate a bit, when one just once skims through the alliance contract, one does not need to take another look, because it defines pretty well what we need to do. However, it does not involve any complex clauses about fines or anything because there is no need for such things, since we are in this together. The contract is really clear, which is a good thing, since in conventional cases, one needs to interpret the contract with a magnifying glass" (Matinheikki et al., 2019, p. 311).

\section{Conclusions}

Evidence from four research studies has been presented to explain how cultural-cognitive expertise of IPD practitioners may be developed. Personal and organisational characteristics together with features of the IPD-alliancing contract arrangements contribute to an individual and team's capacity and capability to make sense of IPD contract, governance arrangements and practice based regulatory pillar elements. As Figure 4 illustrates, this enables them to enhance their cultural-cognitive expertise that in turn empowers them to take the initiative and being resilient to unexpected events that requires them to adopt an emergent strategy approach (Hällgren and Wilson, 2007; Jarzabkowski, 2004; Mintzberg, 1987) to cope with plan diversions.

Each Figure 4 element is necessary for effective cultural-cognitive sensemaking to achieve a committed, coordinated, integrated and unified best-for-project mindset. A deficiency in any one element compromises achieving that result.

This paper answers the research question Which mechanisms, behaviours and processes actively support integrated project delivery participants to make sense of project governance rules and protocols in a way that enables them to collaborate and forge common goals that results in unified collective action?

Several salient concepts and theories were used to explain how mechanisms, behaviours and processes support sensemaking of the governance rules, protocols, KRAs and other regulative institutional pillar that are considered as culturalcognitive competencies. Table 3 summarises these from the individual and alliance united team perspective.

The answer to the research question is summarised as follows:

1. Personal attributes of project participants are vital, particularly their culturalcognitive expertise. The evidence on how project teams are selected in alliances for example suggests that care is taken to select team members who demonstrate an open mind, have good perspective taking abilities and the capacity, motivation and ability to collaborate through dialogue to make sense of complex issues.

2. The workplace environment needs to support initiative taking, learning from mistakes, be recognised as having a noblame culture and have low power and information asymmetry. This enables people to engage in dialogue, free of fear of being punished or not respected for their opinion or position when engaging in dialogue. The workplace needs to present fertile ground for personal and cross-team cultural-cognitive expertise in order to exercise appropriate agency. 
Table 3 Conceptual cultural-cognitive competencies impacting sensemaking

\begin{tabular}{|c|c|c|}
\hline Concepts and theories & $\begin{array}{l}\text { Applied at the individual and individual } \\
\text { team level }\end{array}$ & $\begin{array}{l}\text { Applied through dialogue at the alliance } \\
\text { team level }\end{array}$ \\
\hline $\begin{array}{l}\text { The regulatory institutional theory } \\
\text { pillar (Figure 1): } \\
\text { Governance and governmentality }\end{array}$ & $\begin{array}{l}\text { Figure } 2 \text {, the governmentality map, } \\
\text { illustrates how individuals might perceive } \\
\text { the level of agency, constraint and context } \\
\text { they face. }\end{array}$ & $\begin{array}{l}\text { Individual perceptions and interpretations } \\
\text { could be modified through dialogue with } \\
\text { others to gain a better understanding of } \\
\text { cultural impact factors. }\end{array}$ \\
\hline $\begin{array}{l}\text { The normative institutional theory } \\
\text { pillar (Figure 1): }\end{array}$ & $\begin{array}{l}\text { Individuals perceive their obligations and } \\
\text { actions being impacted by their cultural } \\
\text { norms. Having experienced roles played by } \\
\text { other teams helps them understand other } \\
\text { perspectives. }\end{array}$ & $\begin{array}{l}\text { Fluidity of cross-disciplinary experience } \\
\text { combined with dialogue can have a } \\
\text { significant impact on how cultural norms } \\
\text { (national, individual and professional) may } \\
\text { be formed and re-formed. }\end{array}$ \\
\hline $\begin{array}{l}\text { The cultural-cognitive } \\
\text { institutional theory pillar } \\
\text { (Figure 1): }\end{array}$ & $\begin{array}{l}\text { Individuals vary in their sense of agency, } \\
\text { their KSAEs, resilience and reflective } \\
\text { capacity. The alliance agreement supports } \\
\text { critical thinking and low power-information } \\
\text { asymmetry. }\end{array}$ & $\begin{array}{l}\text { The alliance agreement language is highly } \\
\text { supportive of interpreting the regulative } \\
\text { pillar through the integrated team's } \\
\text { joint accountability to a best-for-project } \\
\text { outcome. }\end{array}$ \\
\hline $\begin{array}{l}\text { Expertise and wisdom } \\
\text { development (Table 1) and } \\
\text { cultural-cognitive capability } \\
\text { (Figure 3): }\end{array}$ & $\begin{array}{l}\text { Individuals perceive the regulatory pillar } \\
\text { aspects of the work based upon their level of } \\
\text { experience and understanding of the project } \\
\text { scope and complexity. Personal attributes } \\
\text { such as bravery and willingness to be } \\
\text { innovative also play a role. }\end{array}$ & $\begin{array}{l}\text { Team level maturity of expertise and } \\
\text { wisdom within an alliance, with its } \\
\text { supportive behavioural regulatory } \\
\text { framework, allows and expects mentoring, } \\
\text { coaching and continuous learning of } \\
\text { individuals through dialogue and the united } \\
\text { team perspective. }\end{array}$ \\
\hline $\begin{array}{l}\text { Perceptions of complexity and } \\
\text { required action (The Cynefin } \\
\text { Framework discussion). }\end{array}$ & $\begin{array}{l}\text { Individuals will moderate their perception of } \\
\text { a project's complexity, and how to act, based } \\
\text { in part on their expertise and professional } \\
\text { maturity. This influences their views on } \\
\text { how they should react to situations where } \\
\text { the regulatory pillar aspects are vague or } \\
\text { unclear. }\end{array}$ & $\begin{array}{l}\text { The alliance agreement behaviour } \\
\text { requirements and the role of dialogue from } \\
\text { the united team perspective, can support a } \\
\text { highly sophisticated and nuanced cultural- } \\
\text { cognitive view. This is particularly evident } \\
\text { at the TOC planning stage and when } \\
\text { taking resilient action to obviate or address } \\
\text { unanticipated events. }\end{array}$ \\
\hline
\end{tabular}

3. The contractual form adopted is vital in encouraging and supporting collaboration and dialogue between individuals and teams when making sense of challenges and opportunities resulting from operating regulatory arrangements.

4. Effective cultural-cognitive expertise requires both workplace practice support but also mentoring, training and development to hone collaboration and dialogue enabling skills.

This paper's academic contribution is its focus on how institutional theory within an IPD context explains behaviours and actions of individuals and groups and its answer to the research question. Few previous IPD studies have been able to draw upon qualitative data and insights from as many global experts in IPD practice and theory (80 expert practitioners and 14 expert academics). A new contribution is made through consideration of how IPD participants make sense of their world using institutional theory, the Cynefin Framework and career maturity and development theory. It contributes to practice by explaining how alliancing, and similar IPD project delivery forms, result in enhanced initiative and resilience of individuals and teams.

\section{References}

Aapaoja, A., Herrala, M., Pekuri, A. and Haapasalo, H. (2013), "The characteristics of and cornerstones for creating integrated teams", International Journal 
of Managing Projects in Business, Vol. 6 No. 4, pp. 695-713. 10.1108/IJMPB-09-2012-0056

Ahlstrom, D. and Wang, L.C. (2009), "Groupthink and France's defeat in the 1940 campaign", Journal of Management History, Vol. 15 No. 2, pp. 159-177. 10.1108/17511340910943804

American Institute of Architects - AIA California Council. (2007), Integrated project delivery: $a$ guide. Sacremento, CA: American Institute of Architects.

Andersen, B., Klakegg, O.J. and Walker, D.H.T. (2020), "IPD Governance Implications". In: Walker D. H. T, Rowlinson S, eds. The Routledge Handbook of Integrated Project Delivery. Abingdon, Oxon: Routledge. pp. 417-438.

Auditor-General of the Australian National Audit Office. (2000), Construction of the National museum of Australia and the Australian Institute of Aboriginal and Torres Strait Islander studies, audit report. vol. 34. Canberra, Australia: Australian National Audit Office. pp. 1999-2000.

Biesenthal, C., Clegg, S., Mahalingam, A. and Sankaran, S. (2018), "Applying institutional theories to managing megaprojects", International Journal of Project Management, Vol. 36 No. 1, pp. 43-54. 10.1016/j.ijproman.2017.06.006

Brady, T., Davies, A. and Gann, D.M. (2005), "Creating value by delivering integrated solutions", International Journal of Project Management, Vol. 23 No. 5, pp. 360-365. 10.1016/j.ijproman.2005.01.001 Bygballe, L.E., Dewulf, G. and Levitt, R.E. (2015), "The interplay between formal and informal contracting in integrated project delivery", Engineering Project Organization Journal, Vol. 5 No. 1, pp. 22-35. 10.1080/21573727.2014.992014

Cicmil, S. (2003), From instrumental rationality to practical wisdom. PhD Thesis. Leicester, Simon, de Montfort University.

Department of Infrastructure and Transport. (2011), National Alliance Contracting Guidelines Note 1 Language in Alliance Contracting: A Short Analysis of Common Terminology. Department of Infrastructure and Transport A. C. G. Canberra, Commonwealth of Australia. p. 18.

Department of Treasury and Finance Victoria. (2009), Guidance Note No 1 Language in Alliance Contracting: A Short Analysis of Common Terminology. Melbourne, Victoria: Department of Treasury and Finance. p. 15.

Department of Treasury and Finance Victoria. (2010), The Practitioners' Guide to Alliance Contracting. Melbourne, Victoria: Department of Treasury and Finance. p. 161.
Dreyfus, H.L., Dreyfus, S.E. and Athanasiou, T. (1986), Mind over machine: the power of human intuition and expertise in the era of the computer. New York: Free Press.

Dreyfus, S.E. (2004), "The Five-Stage model of adult skill acquisition", Bulletin of Science, Technology \& Society, Vol. 24 No. 3, pp. 177-181. $10.1177 / 0270467604264992$

Dietz, T. and Burns, T.R. (1992), "Human agency and the evolutionary dynamics of culture", Acta Sociologica, Vol. 35 No. 3, pp. 187-200. 10.1177/000169939203500302

Duryan, M. and Smyth, H. (2019), "Cultivating sustainable communities of practice within hierarchical bureaucracies", International Journal of Managing Projects in Business, Vol. 12 No. 2, pp. 400-422. 10.1108/IJMPB-03-2018-0040

Fischer, M., Khanzode, A., Reed, D. and Ashcraft, H.W. (2017), Integrating Project Delivery. Hoboken, NJ: Wiley.

Good, D.J., Lyddy, C.J., Glomb, T.M., Bono, J.E., Brown, K.W., Duffy, M.K., Baer, R.A., Brewer, J.A. and Lazar, S.W. (2016), "Contemplating Mindfulness at Work:An Integrative Review", Journal of Management, Vol. 42 No. 1, pp. 114-142.

Hall, D.M. and Scott, W.R. (2019), "Early stages in the institutionalization of integrated project delivery", Project Management Journal, Vol. 50 No. 2, pp. 128-143. 10.1177/8756972818819915

Henisz, W.J., Levitt, R.E. and Scott, W.R. (2012), "Toward a unified theory of project governance: economic, sociological and psychological supports for relational contracting", Engineering Project Organization Journal, Vol. 2 No. 1-2, pp. 37-55. 10.1080/21573727.2011.637552

Hofstede, G. (2001), Culture's Consequences: Comparing values, behaviors, institutions and organizations across nations. Thousand Oaks, CA: Sage.

House, R.J., Hanges, P.J., Javidan, M., Dorfman, P.W. and Gupta, V. (2004), Culture, Leadership, and Organizations - The GLOBE Study of 62 Societies. Thousand Oaks, CA: Sage Publication Ltd.

Hällgren, M. (2010), “Groupthink in temporary organizations", International Journal of Managing Projects in Business, Vol. 3 No. 1, pp. 94-110. 10.1108/17538371011014044

Hällgren, M. and Wilson, T.L. (2007), "Mini-muddling: learning from project plan deviations", Journal of Workplace Learning, Vol. 19 No. 2, pp. 92-107. $10.1108 / 13665620710728475$

Jarzabkowski, P. (2004), "Strategy as practice: Recursiveness, adaptation, and Practices-in-Use", 
Organization Studies, Vol. 25 No. 4, pp. 529-560. 10.1177/0170840604040675

Kurtz, C.F. and Snowden, D.J. (2003), "The new dynamics of strategy: sense-making in a complex and complicated world", IBM Systems Journal, Vol. 42 No. 3, pp. 462-483. 10.1147/sj.423.0462

Lahdenperä, P. (2019), "Longitudinal View of Adopting Project Alliancing: Case Finland", 10th Nordic Conference on Construction Economics and Organization, Irene L. and W. Emlyn. Emerald Publishing Limited. 129-136.

Lave, J. and Wenger, E.C. (1991), Situated Learning - Legitimate Peripheral Participation. Cambridge: Cambridge University Press.

Lloyd-Walker, B.M., Crawford, L., French, E. and Walker, D.H.T. (2020), "People, Careers and IPD Human Resource Management". In: Walker D. H. T, Rowlinson S, eds. The Routledge Handbook of Integrated Project Delivery. Abingdon, Oxon: Routledge. pp. 245-263.

Lloyd-walker, B.M., Mills, A.J. and Walker, D.H.T. (2014), "Enabling construction innovation: the role of a no-blame culture as a collaboration behavioural driver in project alliances", Construction Management and Economics, Vol. 32 No. 3, pp. 229-245. 10.1080/01446193.2014.892629

Mahalingam, A., Levitt, R.E. and Scott, W.R. (2011), "Rules versus results: sources and resolution of institutional conflicts on Indian metro railway projects”. In: Levitt R. E, Orr R. J, Scott W. R, eds. Global Projects: Institutional and Political Challenges. Cambridge: Cambridge University Press. pp. 113-134.

Matinheikki, J., Aaltonen, K. and Walker, D. (2019), "Politics, public servants, and profits: institutional complexity and temporary hybridization in a public infrastructure alliance project", International Journal of Project Management, Vol. 37 No. 2, pp. 298-317. 10.1016/j.ijproman.2018.07.004

Matinheikki, J., Pesonen, T., Artto, K. and Peltokorpi, A. (2017), "New value creation in business networks: the role of collective action in constructing system-level goals", Industrial Marketing Management, Vol. 67, pp. 122-133. 10.1016/j.indmarman.2017.06.011

Mayer, R.C., Davis, J.H. and Schoorman, F.D. (1995), "An integrative model of organizational trust", Academy of Management Review, Vol. 20 No. 3, pp. 709-734. 10.5465/ amr.1995.9508080335

Mintzberg, H. (1987), "Crafting Strategy", Harvard Business Review, Vol. 65 No. 4, pp. 66-75.
Morris, P.W.G. and Geraldi, J. (2011), "Managing the institutional context for projects", Project Management Journal, Vol. 42 No. 6, pp. 20-32. 10.1002/ pmj.20271

Mullaly, M. (2014), "The role of agency in project initiation decisions", International Journal of Managing Projects in Business, Vol. 7 No. 3, pp. 518-535. 10.1108/IJMPB-09-2013-0043

Müller, R. (2017), "Chapter 2 - Organizational Project Governance”. In: Müller R, ed, Governance and Governmentality for Projects: Enablers, Practices, and Consequences. Abingdon, Oxon: Routledge. pp. 24-37.

Müller, R., Zhai, L., Wang, A. and Shao, J. (2016), “A framework for governance of projects: governmentality, governance structure and projectification", International Journal of Project Management, Vol. 34 No. 6, pp. 957-969. 10.1016/j.ijproman.2016.05.002

Orr, J. (1990), Talking about machines: an ethnography of a modern job. PhD Thesis. Ithaca, NY, Cornell University.

Parker, S.K., Atkins, P. and Axtell, C. (2008), "Building better work places through individual perspective taking: A fresh look at a fundamental human process". In: Hodgkinson G. P, Ford J. K, eds. International Review of Industrial and Organizational Psychology. Chichester: John Wiley \& Sons Inc. pp. 149-196.

Provera, B., Montefusco, A. and Canato, A. (2010), "A 'No Blame' Approach to Organizational Learning", British Journal of Management, Vol. 21 No. 4, pp. 1057-1074. 10.1111/j.1467-8551.2008.00599.x

Ross, J. (2003), "Introduction to project alliancing", Alliance Contracting Conference, Sydney: Project Control International Pty Ltd30 April 2003. 43.

Rowlinson, S. and Walker, D.H.T. (2020), "Value from an IPD perspective". In: Walker D. H. T, Rowlinson S, eds. The Routledge Handbook of Integrated Project Delivery. Abingdon, Oxon: Routledge. pp. 69-83.

Schein, E.H. (1985), Organisational Culture and Leadership. San Francisco: Jossey Bass.

Schein, E.H. (1996), "Three Cultures of Management: The Key to Organizational Learning”, Sloan Management Review, Vol. 38 No. 1, pp. 9-20.

Scott, W.R. (2001), Institutions and organizations. Thousand Oaks, Calif.: London, Sage.

Scott, W.R. (2014), Institutions and organizations. Thousand Oaks, Calif: London, Sage.

Senge, P.M. (1990), The Fifth Discipline - The Art \& Practice of the Learning Organization. Sydney, Australia: Random House.. 
Smits, K. and van Marrewijk, A. (2012), "Chaperoning: practices of collaboration in the Panama canal expansion program", International Journal of Managing Projects in Business, Vol. 5 No. 3, pp. 440-456. 10.1108/17538371211235317

Snowden, D.J. and Boone, M.E. (2007), “A Leader's Framework for Decision Making", Harvard business review, Vol. 85 No. 11, pp. 69-76.

Somerville, P. (2012), "Critical Realism”. In: Smith S. $\mathrm{J}$, ed, International Encyclopedia of Housing and Home. San Diego: Elsevier. pp. 291-295.

Szulanski, G. (1996), "Exploring internal stickiness: impediments to the transfer of best practice within the firm", Strategic Management Journal, Vol. 17 No. S2, pp. 27-43. 10.1002/smj.4250171105

Trompenaars, F. (1993), Riding the Waves of Culture: Understanding Cultural Diversity in Business. London: Economics Books.

Tukiainen, S. and Granqvist, N. (2016), "Temporary organizing and institutional change", Organization Studies, Vol. 37 No. 12, pp. 1819-1840. 10.1177/0170840616662683

van Marrewijk, A. and Smits, K. (2016), “Cultural practices of governance in the Panama canal expansion Megaproject", International Journal of Project Management, Vol. 34 No. 3, pp. 533-544. 10.1016/j. ijproman.2015.07.004

Walker, D.H.T., Hampson, K. and Peters, R. (2002), "Project alliancing vs project partnering: a case study of the Australian National museum project", Supply Chain Management: An International Journal, Vol. 7 No. 2, pp. 83-91. 10.1108/13598540210425830

Walker, D.H.T. and Lloyd-Walker, B.M. (2015), Collaborative Project Procurement Arrangements. Newtown Square, PA: Project Management Institute.
Walker, D.H.T. and Lloyd-Walker, B.M. (2020a), "Characteristics of IPD: A Framework Overview". In: Walker D. H. T, Rowlinson S, eds. The Routledge Handbook of Integrated Project Delivery. Abingdon, Oxon: Routledge. pp. 20-40.

Walker, D.H.T., Lloyd-Walker, B.M. and Harley, J. (2016), Understanding the alliance target Outturn cost process and its implications, Melbourne, Australia, centre for integrated project solutions, school of property, construction and project management. Melbourne, Australia: RMIT University. p. 77.

Walker, D.H.T., Matinheikki, J. and Maqsood, T. (2018), Level crossing removal authority package 1 case study, Melbourne, Australia, BIM+ Research group, school of property, construction and project management. Melbourne, Australia: RMIT University. p. 38.

Walker, D. and Jacobsson, M. (2014), "A rationale for alliancing within a public-private partnership", Engineering, Construction and Architectural Management, Vol. 21 No. 6, pp. 648-673. 10.1108/ECAM09-2013-0087

Walker, D.H.T. and McCann, A. (2020b), "IPD and TOC Development". In: Walker D. H. T, Rowlinson S, eds. The Routledge Handbook of Integrated Project Delivery. Abingdon, Oxon: Routlidge. pp. 581-604.

Walker, D.H.T. and Rowlinson, S. (2020c), "IPD from a culture perspective". In: Walker D. H. T, Rowlinson S, eds. The Routledge Handbook of Integrated Project Delivery. Abingdon, Oxon: Routledge. pp. 197-218.

Weick, K.E., Sutcliffe, K.M. and Obstfeld, D. (2005), "Organizing and the process of Sensemaking", Organization Science, Vol. 16 No. 4, pp. 409-421. 10.1287/orsc. 1050.0133 